\title{
High reprint orders in medical journals and pharmaceutical industry funding: case-control study
}

\author{
(c) $(1)(9)$ OPEN ACCESS
}

\author{
Adam E Handel clinical fellow ${ }^{12}$, Sunil V Patel surgical resident ${ }^{34}$, Julia Pakpoor medical student ${ }^{12}$, \\ George C Ebers professor of neurology ${ }^{12}$, Ben Goldacre clinical research fellow ${ }^{3}$, Sreeram V \\ Ramagopalan research fellow ${ }^{356}$
}

\begin{abstract}
${ }^{1}$ Wellcome Trust Centre for Human Genetics, University of Oxford, Oxford, UK; ${ }^{2}$ Nuffield Department of Clinical Neurosciences (Clinical Neurology), University of Oxford, John Radcliffe Hospital, Oxford, UK; ${ }^{3}$ Department of Epidemiology, London School of Hygiene and Tropical Medicine, London, UK; ${ }^{4}$ Department of Surgery, London Health Sciences Centre, London, ON, Canada; ${ }^{5}$ Department of Physiology, Anatomy and Genetics and Medical Research Council Functional Genomics Unit, University of Oxford, Oxford, UK; ${ }^{6}$ Blizard Institute, Queen Mary University of London, Barts and The London School of Medicine and Dentistry, London, UK
\end{abstract}

\begin{abstract}
Objectives To assess the extent to which funding and study design are associated with high reprint orders.

Design Case-control study.

Setting Top articles by size of reprint orders in seven journals, 2002-09.

Participants Lancet, Lancet Neurology, Lancet Oncology (Lancet Group), BMJ, Gut, Heart, and Journal of Neurology, Neurosurgery \& Psychiatry (BMJ Group) matched to contemporaneous articles not in the list of high reprint orders.
\end{abstract}

Main outcome measures Funding and design of randomised controlled trials or other study designs.

Results Median reprint orders for the seven journals ranged from 3000 to 126350 . Papers with high reprint orders were more likely to be funded by the pharmaceutical industry than were control papers (industry funding versus other or none: odds ratio $8.64,95 \%$ confidence interval 5.09 to 14.68 , and mixed funding versus other or none: $3.72,2.43$ to 5.70 ).

Conclusions Funding by the pharmaceutical industry is associated with high numbers of reprint orders.

\section{Introduction}

Reprints of published articles are a potential valuable means of disseminating information. ${ }^{1}$ Many individuals and organisations may request reprints, including the authors of the articles themselves, other members of the scientific community, study sponsors, and pharmaceutical companies. The pharmaceutical industry is thought to be the largest purchaser of reprints. After gifts and drug samples, reprints are the most common form of promotional material circulated among doctors by pharmaceutical companies. ${ }^{2}$

Because pharmaceutical companies may buy from journals copies of articles they have funded, reprints of published articles have been suggested as a possible source of conflict of interest that could lead to publication bias. Orders can be worth large sums of money and could potentially influence the chance of a paper being accepted, especially with the current organisational framework, under which editors can be responsible for the journal's content and its finances. ${ }^{3}$ Studies sponsored by the pharmaceutical industry are also more likely to be published in higher impact factor journals than are studies without industry funding. ${ }^{4}$

Data on the numbers of reprints ordered are scarce. One study examined the characteristics of articles published in the Lancet in 1998 in the top 21 of reprint orders and compared these with a set of control articles from the same journal. ${ }^{5}$ Reprint orders were not reported in detail, but less than $25 \%$ were stated to concern over 100000 copies. Studies sponsored by the pharmaceutical industry were marginally significantly over-represented in the high reprint group compared with the control articles. Using more recent data we report the number of reprints ordered for the top articles by reprint order in medical journals, identify the sponsors and designs of these studies, and quantify the possible financial implications for journals.

\section{Methods}

We emailed the editors in chief of the Journal of the American Medical Association, Lancet, New England Journal of Medicine, 
Annals of Internal Medicine, and BMJ to supply details of the top articles by size of reprint orders (the high reprint group).

For each journal we selected control articles immediately before the high reprint article from the same section of the same issue or, where this was not possible, the first article in the same section of the previous issue. The control article was always of the same type as the high reprint article (research article, editorial, etc) and could not be in the high reprint group. We discarded reprint orders for articles when suitable controls could not be found or financial disclosures were lacking. Several articles appeared multiple times in the top reprint groups of successive years; we counted these articles only once but summed the reprint orders. Table $1 \Downarrow$ shows the total numbers of high reprint and control articles for each journal.

\section{Study design and source of funding}

Each study was categorised as either a randomised control trial or another study design (including meta-analysis, observational study, basic science, and commentary). We extracted the source of funding from the acknowledgments or conflicts of interest section and classified this into industry funding, mixed funding, or other sources of funding. Research articles were classified as being industry funded if all of the funding for the study was supplied by a pharmaceutical company, and mixed if some of the funding was supplied by a pharmaceutical company. Other article types, such as commentaries, were classified as being industry funded if the body of the article referred to a pharmaceutical product and the author or authors received funding, honorariums, or salaries from the pharmaceutical company related to that product. Two authors (AEH and JP) independently appraised the funding status of all articles and compared results. Discrepancies were resolved by consensus with a third author (SVR).

The costs for the reprint orders were obtained directly from the BMJ and Lancet on 15 August 2011.

\section{Statistical analysis}

We used logistic regression to calculate odds ratios and 95\% confidence intervals for comparisons between the high reprint and control groups, using study design and funding as explanatory variables. The data were analysed as clustered data, with journal and issue as the cluster unit. Using the random effects model we calculated the $\mathrm{I}^{2}$ value to assess heterogeneity between the journals. We considered $\mathrm{P}$ values $<0.05$ as significant. Statistical analyses were done in Stata 12.0.0.

\section{Results}

\section{Journal responses}

Only the Lancet Group and BMJ Group responded to the request for data, providing the top 20 reprint articles each year for the Lancet and BMJ, top 10 reprint articles each year for Heart, Gut, and the Journal of Neurology, Neurosurgery \& Psychiatry, and the top five reprint articles each year for Lancet Neurology and Lancet Oncology.

Lancet initially provided data from 2002 to 2009, and thus for consistency data were requested for this period from the other journals and used in all analyses.

\section{Reprint orders}

Table 1 shows the average reprint orders for the top reprinted articles by journal. Lancet had by far the highest median number of reprints, with a median order of 126350 for its high reprint group (range $24000-835100)$. The BMJ and Lancet Oncology had median reprint orders greater than 10000 (13 248 and 10 500 , respectively), whereas the other journals had median reprint orders of 5200 or less. Notably, $62.3 \%$ of reprint orders in Lancet were in excess of 100000 copies, higher than the $24 \%$ found by other researchers. ${ }^{5}$ Table $2 \Downarrow$ gives the proportion of all reprint orders in excess of 100000 copies.

\section{Funding and study design}

Table $3 \Downarrow$ summarises the characteristics of the articles in the high reprint and control groups. (See the supplementary file for a full list of the case and control articles, along with their categorisation according to funding.) The inter-rater agreement for categorisation by funding and study design was excellent $(\kappa=0.97)$. When all journal data were pooled, high reprint order papers were more likely to be funded by the pharmaceutical industry than control papers: industry funding versus other or none, odds ratio 8.64 (95\% confidence interval 5.09 to 14.38 ); mixed funding versus other or none, 3.72 (2.43 to 5.70). Articles with high reprint orders were no more likely to be randomised controlled trials than other study designs (1.04, 0.70 to 1.54$)$.

Considering each journal individually, papers with high reprint orders were significantly more likely to be funded by industry in all journals except $G u t$, where the trend was for high reprint papers to be funded by industry. The effect of industry funding on being a high reprint paper was similar across all studies $\left(\mathrm{I}^{2}=0 \%, \mathrm{P}=0.74\right)$, as was the effect of mixed funding $\left(\mathrm{I}^{2}=0 \%\right.$, $\mathrm{P}=0.70)$. Gut was the only journal where randomised controlled trials were significantly more likely to have high reprint orders, with Heart trending towards a similar association. The effect of study design was similar across all journals $\left(\mathrm{I}^{2}=16.9 \%\right.$, $\mathrm{P}=0.30$ ).

\section{Financial implications}

Table $4 \Downarrow$ presents the cost for the median and largest reprint order for each journal. This ranged from $£ 4002$ ( $€ 4962 ; \$ 6276$ ) (Gut) to $£ 1551794$ (Lancet).

\section{Discussion}

High reprint articles, irrespective of journal, were significantly more likely to be sponsored by the pharmaceutical industry. General medical journals had more reprint orders than speciality journals. Some of the reprint orders were substantial, equating to a large amount of income generated. Thus reprint orders could potentially be a source of publication bias, although our study was not designed with this in mind. An overall association of study design with reprint orders was not apparent, although this might differ by journal.

\section{Limitations of the study}

The key limitation of our study was the scope of the data. Firstly, we were only able to obtain data from one general medical journal that does not use open access publishing (the $B M J$ publishes all research journals as open access), as our requests for data were declined by other journals approached. The editor in chief of the Journal of the American Medical Association explained that the information requested was proprietary and would not be released to anyone. The managing director of publishing at the New England Journal of Medicine explained that its business practice precluded sharing data on reprint orders. The vice president of publishing for the Annals of Internal Medicine stated that it would require too much work to compile the data. For the Journal of the American Medical 
Association, New England Journal of Medicine, and Annals of Internal Medicine we were told that the editor in chief does not have involvement in specific data on reprint orders. It is unknown how representative the Lancet and $B M J$ are of other medical journals.

Secondly, we analysed data only for the top 5-20 most highly ordered papers. It is possible that the excess of industry funded studies is less pronounced or even reversed outside the most highly reprinted papers. The impact of such a difference would depend on how the overall income from the "long tail" of a large number of studies with lower reprint orders compares with the income from these high reprint papers. Addressing such a question would require a cohort study of reprint orders for all papers published by a journal: this would be a far larger project than this case-control study and would require access to an even larger quantity of commercial data from journals.

\section{Background from other studies}

We are aware of one study dealing with this specific research question, which examined the characteristics of articles published in the Lancet during 1998 and focused primarily on analysing citation patterns. ${ }^{5}$ That study reported a larger over-representation of industry sponsored studies in the high reprint group compared with the control group (12/21 v 5/21 odds ratio $4.27,95 \%$ confidence interval 1.13 to $16.05, \mathrm{P}=0.03$ ). This is lower than we observed - the high reprint articles in the Lancet and all journals combined were, respectively, 12 and eight more times likely to be funded by a pharmaceutical company.

\section{Conclusions and policy implications}

We have identified a potential source of publication bias among several medical journals. This will need confirmation from data generated by other publication groups and further research. We emphasise that there is currently no evidence that the potential for future reprint orders influences decisions to publish particular articles. This is especially true given that reprint orders are only realised after the publication of studies. Moreover, the patterns of reprint orders may be changing substantially over time (for example, an increase in their use as teaching material), which may obscure any potential bias. However, because reprints provide considerable sources of revenue, we would suggest that data on reprint orders should be made more available generally and that specific data for reprint orders should be included with individual articles.

We thank Richard Horton and Astrid James at the Lancet, Helen Frankish at Lancet Neurology, and Fiona Godlee, Trish Groves, and Alison Walker at the $B M J$ for their openness in providing data on reprints. Contributors: SVR conceived and designed the study. SVP analysed the data. AEH, SVP, JP, GCE, BG, and SVR interpreted the data. AEH and SVR drafted the article. BG and SVR contributed equally to this paper. SVR is guarantor. All authors revised the article and give final approval for publication. No funding bodies had any role in study design, data collection and analysis, decision to publish, or preparation of the manuscript.

Competing interests: All authors have completed the ICMJE uniform disclosure form at www.icmje.org/coi_disclosure.pdf (available on request from the corresponding author) and declare: no support from any organisation for the submitted work; no financial relationships with any organisations that might have an interest in the submitted work in the previous three years; BG has written articles and books on the activities of the pharmaceutical industry.

Ethical approval: Not required.

Data sharing: No additional data available.

1 Vinson DC. Reprint requests for family medicine literature: how do we respond? Fam Med 1990;22:404-5.

2 Stryer D, Bero LA. Characteristics of materials distributed by drug companies. An evaluation of appropriateness. J Gen Intern Med 1996;11:575-83.

3 Smith R. Medical journals are an extension of the marketing arm of pharmaceutical companies. PLoS Med 2005;2:e138.

4 Jefferson T, Di Pietrantonj C, Debalini MG, Rivetti A, Demicheli V. Relation of study quality, concordance, take home message, funding, and impact in studies of influenza vaccines: systematic review. BMJ 2009;338:b354.

5 Hopewell S, Clarke M. How important is the size of a reprint order? Int J Technol Assess Health Care 2003:19:711-4.

Accepted: 27 April 2012

\section{Cite this as: BMJ 2012;344:e4212}

This is an open-access article distributed under the terms of the Creative Commons Attribution Non-commercial License, which permits use, distribution, and reproduction in any medium, provided the original work is properly cited, the use is non commercial and is otherwise in compliance with the license. See: http://creativecommons.org/licenses/by$\mathrm{nc} / 2.0 /$ and http://creativecommons.org/licenses/by-nc/2.0/legalcode. 


\section{What is already known on this topic}

Reprint orders have been suggested as a possible source of publication bias

Articles sponsored by the pharmaceutical industry are more likely to report favourable results than studies sponsored by other funding sources

One small study suggested an over-representation of industry sponsored studies in the top 21 reprint orders in Lancet

\section{What this study adds}

In all seven journals studied, industry sponsored articles were significantly over-represented among those most frequently requested as reprints

Reprint orders represent a large source of income for the Lancet and BMJ

\section{Tables}

Table 1 | Included articles and average reprint orders by journal study design and funding

\begin{tabular}{|c|c|c|c|c|c|c|c|c|c|c|c|c|c|}
\hline \multirow[b]{2}{*}{ Journal } & \multicolumn{6}{|c|}{ High reprint articles } & \multicolumn{6}{|c|}{ Control articles } & \multirow[b]{2}{*}{$\begin{array}{c}\text { Median reprints } \\
\text { and range* }\end{array}$} \\
\hline & No & RCT & $\begin{array}{l}\text { Other } \\
\text { design }\end{array}$ & $\begin{array}{l}\text { Industry } \\
\text { funding }\end{array}$ & $\begin{array}{l}\text { Mixed } \\
\text { funding }\end{array}$ & $\begin{array}{l}\text { Other or } \\
\text { none }\end{array}$ & No & RCT & $\begin{array}{l}\text { Other } \\
\text { design }\end{array}$ & $\begin{array}{l}\text { Industry } \\
\text { funding }\end{array}$ & $\begin{array}{l}\text { Mixed } \\
\text { funding }\end{array}$ & $\begin{array}{l}\text { Other or } \\
\text { none }\end{array}$ & \\
\hline Lancet & 88 & 74 & 14 & 63 & 17 & 8 & 88 & 49 & 39 & 23 & 13 & 52 & $\begin{array}{c}126350(24 \\
000-835100)\end{array}$ \\
\hline $\begin{array}{l}\text { Lancet } \\
\text { Neurology }\end{array}$ & 25 & 8 & 17 & 8 & 9 & 8 & 25 & 3 & 22 & 1 & 5 & 19 & $5200(200-50000)$ \\
\hline $\begin{array}{l}\text { Lancet } \\
\text { Oncology }\end{array}$ & 26 & 10 & 16 & 11 & 4 & 11 & 26 & 7 & 19 & 2 & 3 & 21 & $\begin{array}{c}10500(500-63 \\
500)\end{array}$ \\
\hline$B M J$ & 72 & 19 & 53 & 10 & 19 & 43 & 72 & 13 & 59 & 2 & 10 & 60 & $\begin{array}{c}13248(1000-526 \\
650)\end{array}$ \\
\hline Gut & 46 & 22 & 24 & 18 & 12 & 16 & 46 & 5 & 41 & 3 & 6 & 37 & $\begin{array}{c}3000(1000-322 \\
000)\end{array}$ \\
\hline Heart & 35 & 11 & 24 & 12 & 7 & 16 & 35 & 3 & 32 & 3 & 2 & 12 & $\begin{array}{c}3000(1000-350 \\
000)\end{array}$ \\
\hline $\begin{array}{l}\text { Journal of } \\
\text { Neurology, } \\
\text { Neurosurgery } \\
\& \text { Psychiatry }\end{array}$ & 46 & 17 & 29 & 15 & 17 & 14 & 46 & 3 & 43 & 0 & 5 & 41 & $\begin{array}{c}4008(1000-107 \\
110)\end{array}$ \\
\hline $\begin{array}{l}\text { Combined } \\
\text { journals }\end{array}$ & 339 & 161 & 178 & 45 & 36 & 258 & 339 & 83 & 256 & 6 & 13 & 320 & $\begin{array}{c}13495(200-835 \\
100)\end{array}$ \\
\hline
\end{tabular}

$\mathrm{RCT}=$ randomised controlled trial.

Numbers quoted discount multiple reprint orders placed on same articles.

*Median number of reprints and range include all reprint orders regardless of article duplication. 
Table 2| Percentage of all high reprint order articles with total reprints in excess of 100000 copies by journal

\begin{tabular}{lccccc} 
& & \multicolumn{4}{c}{$>\mathbf{1 0 0} \mathbf{0 0 0}$ reprints (\% of articles with $>\mathbf{1 0 0} \mathbf{0 0 0}$ reprints) } \\
\cline { 3 - 6 } Journal & No of articles & Overall & Industry funding & Mixed funding Other or none \\
Lancet & 88 & $55(62.5)$ & $39(70.9)$ & $10(18.2)$ & $6(10.9)$ \\
\hline Lancet Neurology & 25 & $0(0)$ & $0(0)$ & $0(0)$ & 0() \\
\hline Lancet Oncology & 26 & $1(3.8)$ & $1(100)$ & $0(0)$ & $0(0)$ \\
\hline BMJ & 72 & $10(13.9)$ & $1(10)$ & $4(40)$ & $5(50)$ \\
\hline Gut & 46 & $3(6.5)$ & $3(100)$ & 0 & 0 \\
\hline Heart & 35 & $1(2.9)$ & $1(100)$ & 0 & 0 \\
\hline Journal of Neurology, Neurosurgery \& Psychiatry & 46 & $2(4.3)$ & $1(50)$ & $1(50)$ & 0 \\
\hline
\end{tabular}


Table 3| Multiple logistic regression analysis showing odds ratios of articles being in high reprint versus control groups by design and funding

\begin{tabular}{|c|c|c|c|c|c|}
\hline \multirow[b]{2}{*}{ Journal } & \multicolumn{2}{|c|}{ RCT $v$ other design } & \multirow{2}{*}{$\begin{array}{l}\text { Industry funding } v \text { other or none } \\
\text { Odds ratio }(95 \% \mathrm{Cl})\end{array}$} & \multirow{2}{*}{$\begin{array}{l}\text { Mixed funding } v \text { other or none } \\
\text { Odds ratio }(95 \% \mathrm{Cl})\end{array}$} & \multirow[b]{2}{*}{$P$ value } \\
\hline & Odds ratio $(95 \% \mathrm{Cl})$ & $P$ value & & & \\
\hline Lancet & 1.27 (0.50 to 3.23$)$ & 0.62 & 12.43 (4.63 to 33.38$)$ & $5.13(1.75$ to 15.04$)$ & $<0.001$ \\
\hline Lancet Neurology & 0.87 (0.11 to 7.12$)$ & 0.89 & 15.73 (0.93 to 264.88 ) & 4.06 (0.96 to 17.12$)$ & 0.03 \\
\hline Lancet Oncology & 0.55 (0.11 to 2.64$)$ & 0.46 & 27.36 (2.43 to 307.97$)$ & 2.64 (0.56 to 12.37$)$ & 0.003 \\
\hline$B M J$ & 0.88 (0.35 to 2.21$)$ & 0.78 & 15.64 (1.75 to 139.48$)$ & 2.76 (1.16 to 6.60$)$ & 0.001 \\
\hline Gut & $3.70(1.03$ to 13.31$)$ & 0.045 & 4.31 (1.02 to 18.25$)$ & 2.54 (0.83 to 7.78$)$ & 0.07 \\
\hline Heart & 5.38 (0.98 to 29.36$)$ & 0.052 & 6.00 (1.08 to 33.33$)$ & 4.79 (1.07 to 21.41$)$ & 0.02 \\
\hline $\begin{array}{l}\text { Journal of Neurology, Neurosurgery \& } \\
\text { Psychiatry }\end{array}$ & $1.32(0.23$ to 7.69$)$ & 0.31 & NA & 10.15 (2.79 to 36.88 ) & $<0.001$ \\
\hline Combined journals & $1.04(0.70$ to 1.54$)$ & 0.85 & 8.64 (5.09 to 14.68$)$ & 3.72 (2.43 to 5.70$)$ & $<0.001$ \\
\hline $\mathrm{I}^{2}(\%)(\mathrm{P}$ value $)$ & $16.9(0.30)$ & & $0.0(0.70)$ & $0.0(0.74)$ & - \\
\hline
\end{tabular}

$\mathrm{RCT}=$ randomised controlled trial; $\mathrm{NA}=$ not applicable. 
Table 4| Median and maximum costs for reprint orders

\begin{tabular}{lcc}
\multirow{2}{*}{ Journal } & \multicolumn{2}{c}{ Reprint order cost (£) } \\
\cline { 2 - 3 } BMJ & Median & Maximum \\
\hline Journal of Neurology, Neurology \& Psychiatry & 762458 & 132805 \\
\hline Gut & 4002 & 260055 \\
\hline Heart & 6071 & 334240 \\
\hline Lancet & 287353 & 1551794 \\
\hline Lancet Neurology & 14336 & 87244 \\
\hline Lancet Oncology & 24390 & 104857 \\
\hline
\end{tabular}

$£ 1.00(€ 1.24 ; \$ 1.57)$. 